\title{
PEO nanocomposite polymer electrolyte for solid state symmetric capacitors
}

\author{
NIRBHAY K SINGH ${ }^{1, *}$, MOHAN L VERMA ${ }^{2}$ and MANICKAM MINAKSHI ${ }^{3}$ \\ ${ }^{1}$ Department of Applied Physics, Shri Shankaracharya Institute of Engineering and Technology, \\ Khapri Durg (Chhattisgarh) 490020, India \\ ${ }^{2}$ Computational Nanoionics Research Lab, Department of Applied Physics, FET-SSGI, Shri Shankaracharya Technical \\ Campus, Junwani, Bhilai (Chhattisgarh) 490020, India \\ ${ }^{3}$ School of Engineering and Information Technology, Murdoch University, WA 6150, Australia
}

MS received 28 July 2014; accepted 6 July 2015

\begin{abstract}
Physical and electrochemical properties of polyethylene oxide (PEO)-based nanocomposite solid polymer electrolytes (NPEs) were investigated for symmetric capacitor applications. Nanosize fillers, i.e., $\mathrm{Al}_{2} \mathrm{O}_{3}$ and $\mathrm{SiO}_{2}$ incorporated polymer electrolyte exhibited higher ionic conductivity than those with filler-free composites. The composites have been synthesized by the completely dry (solution-free) hot-press method. The addition of filler in fractional amount to the solid polymer matrix at room temperature further enhances the ionic conductivity. Nature of the NPEs were studied using X-ray diffraction and energy-dispersive spectra analyses. Thermal stability of the resulting electrolyte was analysed by thermogravimetric analysis and differential scanning calorimetric studies. Morphology changes occurred during the addition of fillers was evidenced by scanning electronic microscope images. Solid polymer electrolytes exhibiting these parameters was found to be suitable for solid state capacitors. The results obtained from the electrolytes with an optimum compositions $\left(\mathrm{PEO}_{70} \mathrm{AgI}_{30}\right)_{93}\left(\mathrm{Al}_{2} \mathrm{O}_{3}\right)_{7}$ and $\left(\mathrm{PEO}_{70} \mathrm{AgI}_{30}\right)_{95}\left(\mathrm{SiO}_{2}\right)_{5} \mathrm{used} \mathrm{in}$ the $\left(\mathrm{PEO}_{70} \mathrm{AgI}_{30}\right)_{70}(\mathrm{AC})_{30}$ electrodes for symmetric capacitor applications and their performances were analysed by impedance spectroscopic, Bode plot, cyclic voltammetry, discharge characteristics and leakage current profile.
\end{abstract}

Keywords. Energy dissipative analysis; thermogravimetric analysis; scanning electronic microscopy; differential scanning calorimetry.

\section{Introduction}

Solid polymer electrolytes (SPEs) are of technologically important materials for electrochemical applications ranging from devices such as energy storage units (batteries/fuel cells/supercapacitors) to electro-chromic displays, smart windows and photo-electrochemical solar cells. ${ }^{1-3}$ Capacitors based on activated carbon (AC) electrodes mainly store the charge in an electric double layer (EDL) formed at the electrode/electrolyte interface. The solid-state polymer batteries have attracted the attention because of its striking properties such as flexibility, no leakage of electrolyte, wide operating temperature range of the devices and long-term safety. Hence, the research and development on polymer electrolytes and their usage in lithium ion rechargeable solid state batteries are well identified as they can readily replace the liquid electrolytes currently used in the state of the art energy storage devices. ${ }^{4,5}$ The ionic conductivity owing to polyethylene oxide (PEO) having high molecular weight doped with sodium salts was first reported by Wright. ${ }^{6}$ Since then, diverse studies have been carried out on the complexes of alkaline salts (namely $\mathrm{Li}^{+}, \mathrm{H}^{+}, \mathrm{Na}^{+}$and $\mathrm{K}^{+}$) with PEO

\footnotetext{
*Author for correspondence (sonuphy@yahoo.co.in)
}

to enhance the conductivity of the electrolyte. ${ }^{7,8}$ The technological implications of these electrolytes, with respect to their use in lithium ion batteries and supercapacitors were suggested and realized by many researchers. ${ }^{4,5}$ However, PEO containing alkali metal ions still exhibit relatively low ionic conductivity ${ }^{9}$ to that of liquid/aqueous electrolytes. In general, PEO-based composite electrolyte is a mixture of crystalline and amorphous phases ${ }^{10}$ ratio of which depends to a great extent on compositions of the electrolyte, temperature, and thermal stability. For instance, the presence of crystalline phases at temperatures below $60^{\circ} \mathrm{C}$ inhibits the ion transport while the high ionic conductivity is generally associated with the high temperature amorphous phase. Subsequently studies on PEO-based polymer electrolyte complexes have been carried out while adding inorganic or organic additives, ${ }^{11,12}$ with the aim of reducing the crystallizing ability, improving the mechanical strength and ionic conductivities of the polymer. As noted above, the fast ion transport in solid polymer electrolyte is due to the existence of amorphous phase in the polymer. ${ }^{13}$ Hence, the high surface area inorganic filler such as $\mathrm{Al}_{2} \mathrm{O}_{3}, \mathrm{SiO}_{2}, \mathrm{ZrO}_{2}, \mathrm{TiO}_{2}, \mathrm{CeO}_{2}$ and $\mathrm{MgO}$ are dispersed in the polymer matrices ${ }^{14}$ to form nanocomposite solid polymer electrolyte (NPE). A large improvement in the conductivity of the solid polymer electrolyte was reported for the filler additive by using the combined features of the large 
surface area and Lewis acid-base type interaction through ion-inorganic oxide complex. ${ }^{13,15,16}$ The other alternative way to enhance the conductivity is the incorporation of lowmolecular weight polymers to produce plasticized polymer electrolyte. Therefore, enormous efforts have been made in finding suitable electrolytes that would exhibit high ionic conductivity under ambient conditions with a large operating voltage window that could be used for energy storage devices

In the present paper, the ionic conducting solid polymer electrolyte prepared by the addition of inorganic oxide fillers $\mathrm{Al}_{2} \mathrm{O}_{3}$ and $\mathrm{SiO}_{2}$ to the standard $\mathrm{SPE}\left(\mathrm{PEO}_{70} \mathrm{AgI}_{30}\right)$ system has been reported. The synthesized nanocomposite solid polymer electrolyte has been characterized by several analytical techniques, such as differential scanning calorimetry (DSC) and thermogravimetric (TGA) studies, electrical studies such as conductivity and transport number measurements. The morphology of the obtained nanocomposite polymer electrolyte was characterized by scanning electronic microscopy (SEM) associated with energy dissipative study (EDS). For the symmetric capacitor, polymer-based electrode having composition $\left(\mathrm{PEO}_{70} \mathrm{AgI}_{30}\right)_{1-x}(\mathrm{AC})_{x}(x=10 \leq x \leq 100)$ was used as electrode. In a separate paper, the best AC concentration and the composition $\left(\mathrm{PEO}_{70} \mathrm{AgI}_{30}\right)_{70}(\mathrm{AC})_{30}$ has been optimized and is found to exhibit the highest ionic conductivity $\left(\sigma \sim 1.926 \times 10^{-3} \mathrm{~S} \mathrm{~cm}^{-1}\right.$ ) which is referred as optimum conducting composition and denoted as PAC(OCC). Solid state capacitor based on PEO/AgI/activated carbon (PAC) electrodes in NPEs have been characterized using experimental techniques such as AC impedance spectroscopy, Bode plot, cyclic voltammetry, leakage current and discharge profile. The experimentally prepared capacitors show a signature of capacitor behaviour with lower capacitance up to $3-5 \mathrm{~F} \mathrm{~g}^{-1}$.

\section{Experimental}

\subsection{Preparation of NPEs electrolytes and PAC electrode}

PEO-based $\mathrm{Ag}^{+}$conducting NPEs with the compositions $\left(\mathrm{PEO}_{70} \mathrm{AgI}_{30}\right)_{1-x}\left(\mathrm{Al}_{2} \mathrm{O}_{3}\right)_{x}$ and $\left(\mathrm{PEO}_{70} \mathrm{AgI}_{30}\right)_{1-x}\left(\mathrm{SiO}_{2}\right)_{x}$ (where $x=0 \leq x \leq 10$ ) were prepared by a novel dry (solution free) hot-press method. Solid polymer electrolyte with an optimized composition $\left(\mathrm{PEO}_{70} \mathrm{AgI}_{30}\right)$ termed as 'standard electrolyte' that has been reported in one of our earlier reports ${ }^{17}$ was used as base material. Precursors used were, PEO (having high molecular weight of $6 \times 10^{5}$ with 200-500 ppm, Aldrich), AgI (purity 98\%, Redial laboratory reagent), $\mathrm{Al}_{2} \mathrm{O}_{3}$ (size $10 \mu \mathrm{m}$, purity $\sim 99 \%$, Sigma-Aldrich), $\mathrm{SiO}_{2}$ (size $100<\mathrm{nm}$, purity $\sim 99 \%$, Sigma-Aldrich) and activated carbon (surface area of AC powder was $1400 \mathrm{~m}^{2} \mathrm{~g}^{-1}$, pore volume calculated was $0.45 \mathrm{~cm}^{3} \mathrm{~g}^{-1}$ ). Appropriate $\mathrm{wt} \%$ of these precursors were ground for $10 \mathrm{~min}$ to obtain homogeneity. The grounded mixture was then transferred to furnace and then reacted for about $20 \mathrm{~min}$ at $100^{\circ} \mathrm{C}$ (above the melting point of PEO) to melt and evaporate moisture. The obtained melted product was finally pressed between poles of two stainless-steel blocks at pressure of about $\sim 2 \mathrm{t}$. The resultant thin polymer films of area $\sim 1.85 \mathrm{~cm}^{2}$ having thicknesses of $0.077,0.061,0.069,0.087$ and $0.039 \mathrm{~cm}$ corresponding to respective wt $\% 1,3,5,7$ and 10 of $\mathrm{Al}_{2} \mathrm{O}_{3}$ and $0.040,0.037,0.069,0.031$ and $0.039 \mathrm{~cm}$ corresponding to $\mathrm{wt} \% 1,3,5,7$ and $10 \mathrm{wt} \%$ of $\mathrm{SiO}_{2}$ were obtained. It was observed that for the increasing concentration of inorganic oxide $\left(\mathrm{Al}_{2} \mathrm{O}_{3}\right.$ and $\left.\mathrm{SiO}_{2}\right)$ filler, the thickness of sample decreases, indicating the amorphous nature. The preparation of polymer-based electrode having PAC with the composition $\left(\mathrm{PEO}_{70} \mathrm{AgI}_{30}\right)_{1-x}(\mathrm{AC})_{x}$ (where $\left.x=10 \leq x \leq 50\right)$ was identical to that of the NPE except AC was used in place of nano-filler.

\subsection{Physical and electrochemical characterization}

The ionic conductivity of the prepared NPE sample for different compositions, frequencies and temperatures has been evaluated by the AC impedance spectroscopy technique using LCR Hi-Tester (3532-50, HIOKI, Japan). The activation energy was computed by temperature dependence conductivity curve. Ionic and electronic transference numbers ( $t_{\text {ion }}$ and $t_{\text {ele }}$ ) were evaluated by means of Wagner's DC polarization technique, ${ }^{18,19}$ degree of amorphosity by X-ray diffraction technique using a Philips PW 1710 diffractometer (using $\mathrm{Cu}-\mathrm{K} \alpha$ radiation), surface morphology of the samples through SEM associated with EDS using JEOL JSM-5800 system. The thermal stability was studied by thermogravimetric analysis using TGA instruments (SDT 2960) and DSC (Perkin Elmer). Measurements of capacitors were carried out by impedance spectroscopy, Bode plot, leakage current, and discharge curve profile, capacitance were analysed by cyclic voltammetry using two-cell system in the potential range of $0-1.0 \mathrm{~V}$ at scan rate $1 \mathrm{mV} \mathrm{s}^{-1}$ and constant charge-discharge current of $0.1 \mathrm{~mA}\left(0.05 \mathrm{~A} \mathrm{~g}^{-1}\right)$, respectively.

\section{Results and discussion}

\subsection{Electrochemical characterization: study of transport properties}

3.1a Effect of inorganic oxide filler on the conductivity of NPE: The ionic conductivity of the electrolyte was calculated using the equation $\sigma=t / A R_{\mathrm{b}}$, where $t$ is the thickness of the polymer electrolyte, $A$ the area of the sample, $R_{\mathrm{b}}$ the bulk resistance measured at the intercepting point of plot on the real axis as shown in figure 1. It is clear that the ionic conductivity $(\sigma)$ of both NPEs have been substantially increased with the increase in filler content, reached its optimum value and then starts decreasing with the further addition of filler. The observed behaviour is consistent with those reported for the polymer-based composite electrolytes with different amounts of inorganic fillers. ${ }^{20,21}$ Maximum conductivities $\sigma \sim 5.78 \times 10^{-6}$ and $\sim 7.032 \times 10^{-6} \mathrm{~S} \mathrm{~cm}^{-1}$ were obtained for the compositions $\left(\mathrm{PEO}_{70} \mathrm{AgI}_{30}\right)_{93}\left(\mathrm{Al}_{2} \mathrm{O}_{3}\right)_{7}$ and 


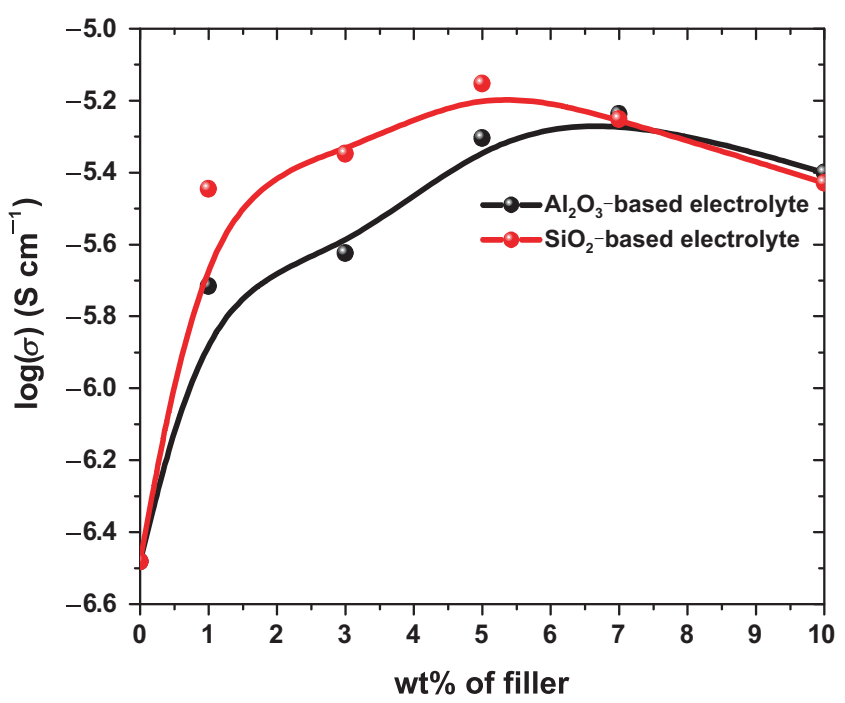

Figure 1. Effect of the concentration of inorganic oxide filler on the ionic conductivity of $\left(\mathrm{PEO}_{70}: \mathrm{AgI}_{30}\right)_{1-x}\left(\mathrm{Al}_{2} \mathrm{O}_{3}\right)_{x}$ and $\left(\mathrm{PEO}_{70}\right.$ : $\left.\mathrm{AgI}_{30}\right)_{1-x}\left(\mathrm{SiO}_{2}\right)_{x}$ nanocomposite solid polymer electrolyte at room temperature.

$\left(\mathrm{PEO}_{70} \mathrm{AgI}_{30}\right)_{95}\left(\mathrm{SiO}_{2}\right)_{5}$, respectively, at room temperature, referred as nanocomposite polymer electrolyte optimum composite composition NPE(OCC)-I and NPE(OCC)-II, respectively. Increase in conductivity is attributed to the number of factors that includes (a) increase in the degree of amorphous content and creation of additional hopping sites for migrating $\mathrm{Ag}^{+}$ions while having more conducting pathways, (b) due to the dissociation of ion pair with the introduction of filler particles and dependence on surface acid-base property of such particles and (c) anion or cation adsorbed at surface leading to higher counter ion concentration in the vicinity of space charge layer and hence higher the conductivity. However, the conductivity is found to decrease after an OCC because on further addition of filler, a continuous non-conductive phase built up by excessive amount of fillers, which behaves as an electrical inert component, ${ }^{22}$ would lead to block Ag ion transport resulting in an increase in total resistance of the NPE film.

3.1b Temperature-dependent conductivity study: To establish the conduction mechanism of the prepared NPE samples, typical impedance plot $\left(Z^{\prime} v s . Z^{\prime \prime}\right)$ for NPE with varying contents of $\mathrm{Al}_{2} \mathrm{O}_{3}$ and $\mathrm{SiO}_{2}$ fillers in SPE at different temperatures are shown in figures 2 and 3, respectively. The impedance plot of both electrolyte systems shows normal impedance behaviour, depressed semicircular arc in the high-frequency range followed by a linear arc in the lowfrequency range. In the complex impedance representation, the presence of linear like curve in the low frequency is the characteristic of a blocking double-layer capacitance otherwise a spike-like curve should have been observed. The high-frequency semicircle corresponds to the bulk properties of the NPEs films. Increase in the temperature decreases the diameter of the semicircle dominantly in the intermediate frequency region and becoming well defined from the original depressed shape and similarly the interfacial resistance in the low-frequency region decreases proportionally. At lower temperatures $<80^{\circ} \mathrm{C}$, the shape of the plots tends to straight line with a large slope indicating the low conducting behaviour of the sample. With the increase in temperature the slope of the curve decreases, bowing up to the real axis with a well-defined semicircle. These results suggest that the migration of ions may occur through the volume of polymer matrix, which can be represented by a resistor. The immobile polymer chains, on the other hand become polarized in the alternating field and can therefore be represented by a capacitor. The ionic migration and bulk polarization are physically in parallel and hence a depressed semicircle at a high frequency is observed. ${ }^{23,24}$

Figure 4 shows the variation of ionic conductivity of the NPE films with inverse temperature plotted for different contents of additives. The observed plot is a typical characteristic of PEO-based amorphous polymer electrolytes showing convex curves. It is clear that in each case, the ionic conductivity has been substantially enhanced with the inverse of the temperature suggesting the amount of amorphosity and the available pores are higher at the higher temperature. It is noted that at a high temperature the chains in the polymer acquire hopping that could lead to the conductivity of the polymer electrolyte system getting high. The temperature dependence of the ionic conductivity exhibited Arrhenius behaviour in the entire temperature range. The Arrhenius plot for NPEs sample, illustrates that the conductivity increases linearly as temperature increases with a slight deviation in the obtained slope. At higher temperature thermal movement of polymer chain segments and the dissociation of salts are improved which increases conductivity. The observed behaviour suggests that the ionic transport is independent of the segmental movement of the NPE. The activation energy (energy required for an ion to begin movement) ' $E_{\mathrm{a}}$ ' is calculated from the experimental plot using the Arrhenius relationship $\sigma=$ $\sigma_{0} \exp \left(-E_{\mathrm{a}} / k T\right)$ where $\sigma_{0}$ is a constant, $E_{\mathrm{a}}$ the activation energy, $k$ the Boltzmann constant and $T$ the absolute temperature. The ' $E_{\mathrm{a}}$ ' calculated for the studied filler content is plotted in figure 5 , it is found that the samples containing $7 \mathrm{wt} \% \mathrm{Al}_{2} \mathrm{O}_{3}$ and $5 \mathrm{wt} \% \mathrm{SiO}_{2}$ additives show least activation energy 0.58 and $0.1 \mathrm{eV}$, respectively, among the contents studied, thus confirming this value as the optimized content for the reported composite (OCC) and are desirable for practical applications. This optimized sample showing the best performance was chosen for solid state capacitor studies and for further physical characterization.

3.1c Ionic transference number measurement: For any battery or capacitor devices, the synthesized polymer electrolyte should perfectly act as an ion conducting medium and as an electronic separator in order to achieve high power densities suitable for potential applications. The transference number of the mobile species in the NPE film has been 

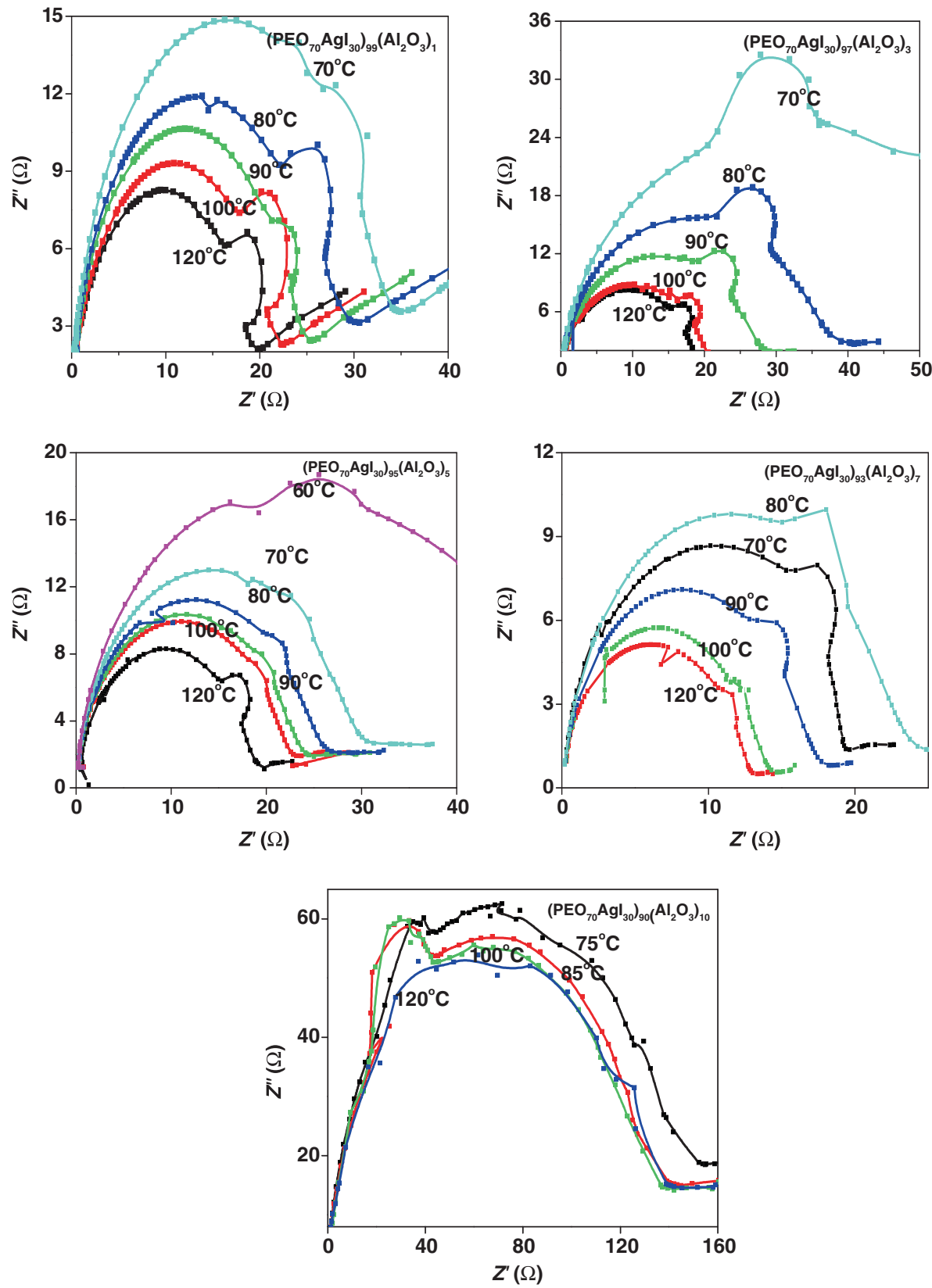

Figure 2. Cole-Cole plot for (PEO70 : $\mathrm{AgI} 30)_{1-x}(\mathrm{Al} 2 \mathrm{O} 3) x(x=0 \leq x \leq 10)$ at different temperatures.

calculated by Wagner's dc-polarization method. ${ }^{19}$ OCC of each electrolyte sample was sandwiched between two brass (blocking) electrode was polarized by applying a constant DC potential $(1.5 \mathrm{~V})$ through a potentiostat across the sample for about $3 \mathrm{~h}$ and the resulting current was monitored. Figure 6 shows the variation of polarization current as a function of time. It shows that steady state current reached after about $1.5 \mathrm{~h}$. The total ionic transference number for both electrolyte is found to be 0.98 , which is very close to unity, which confirms that the material is purely ionic and conductivity of material is predominantly due to ions, while only a negligible contribution comes from electrons. The values of the various parameters, ionic conductivity $(\sigma)$, activation energy
$\left(E_{\mathrm{a}}\right)$ and ion transference number $\left(t_{\text {ion }}\right)$ for both NPE (OCC) are compared with the literatures and tabulated in table 1. It is clearly seen that the additive organic filler enhances the performance of the electrolyte.

\section{1d Electrochemical behaviour of PEO-based electrode:} The electrochemical (capacitive) behaviour of the prepared electrode is also analysed by impedance spectroscopy. The complex impedance plot (or Cole-Cole plot) for $\left(\mathrm{PEO}_{70} \mathrm{AgI}_{30}\right)_{100-x}(\mathrm{AC})_{x}(\mathrm{PAC})$, where $x=10 \leq x \leq 50$, is shown in figure 7. It is a typical electrochemical double layer-like behaviour. The ideal impedance behaviour of 

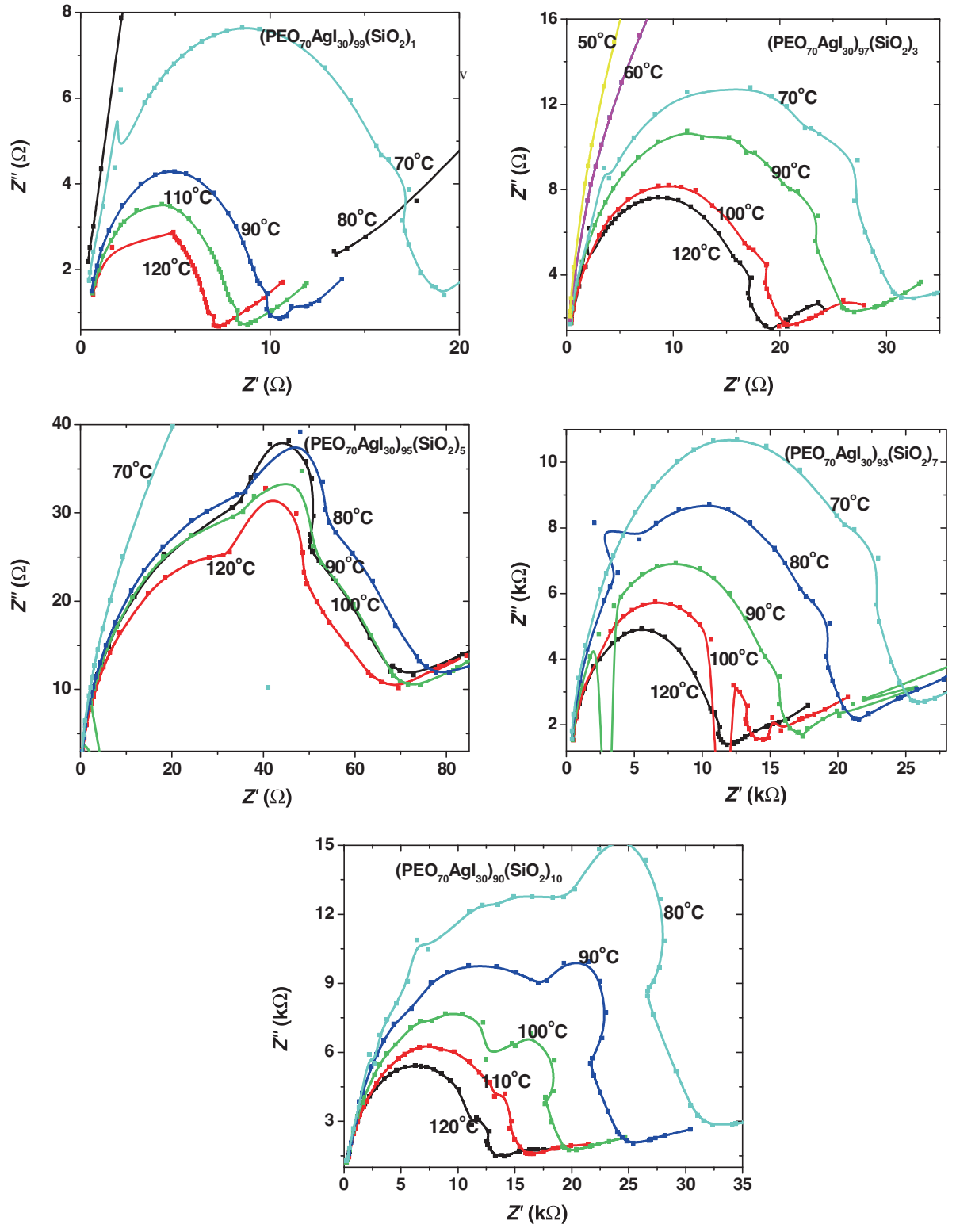

Figure 3. Cole-Cole plot for $\left(\mathrm{PEO}_{70}: \mathrm{AgI}_{30}\right)_{1-x}\left(\mathrm{SiO}_{2}\right) x(x=0 \leq x \leq 10)$ at different temperatures.
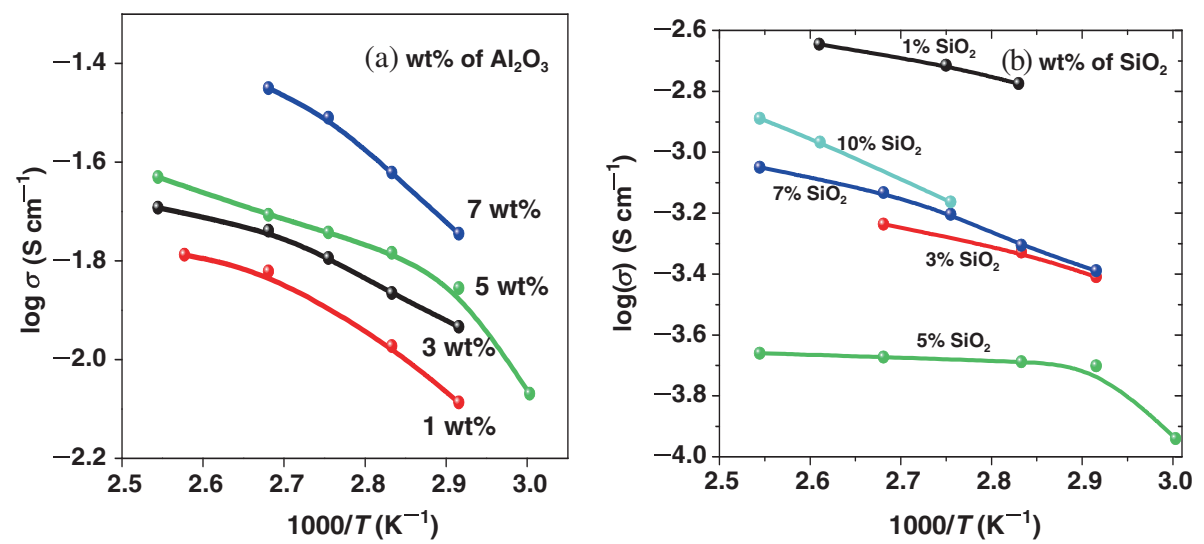

Figure 4. Ionic conductivity of the nanocomposite solid polymer electrolyte with different content levels of fillers: (a) $\mathrm{Al}_{2} \mathrm{O}_{3}$ and (b) $\mathrm{SiO}_{2}$. 
a pure capacitor is a straight line parallel to the imaginary axis $\left(Z^{\prime \prime}\right)$, whereas in a real case, the observed steep rising response owes to the electrode-electrolyte interface. The conductivity measurement on each composition is shown in figure 8, which is the indicative that the composition $\left(\mathrm{PEO}_{70} \mathrm{AgI}_{30}\right)_{70}(\mathrm{AC})_{30}$ has highest conductivity $(\sigma \sim 1.926$ $\times 10^{-3} \mathrm{~S} \mathrm{~cm}^{-1}$ ), and this composition is used as an electrode for each symmetric capacitor and referred to as $\mathrm{PAC}(\mathrm{OCC})$.

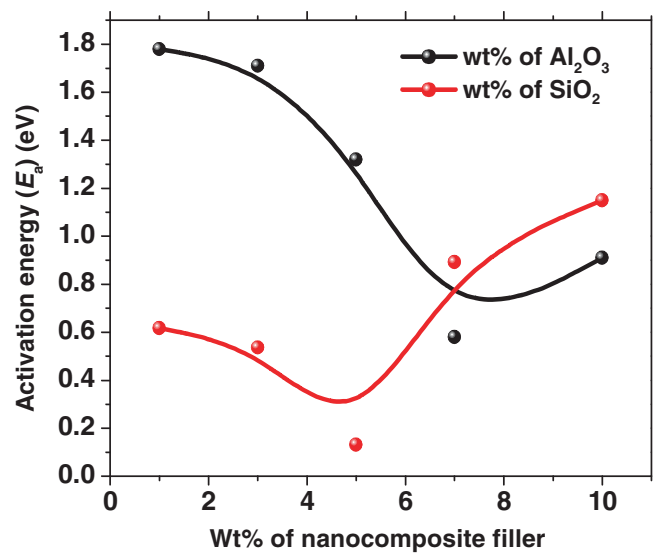

Figure 5. Effect of the concentration of inorganic oxide filler $\left(\mathrm{Al}_{2} \mathrm{O}_{3}\right)$ on the activation energy of $(1-x)(70 \mathrm{PEO}: 30 \mathrm{AgI}): x \mathrm{Al}_{2} \mathrm{O}_{3}$ nanocomposite solid polymer electrolyte.

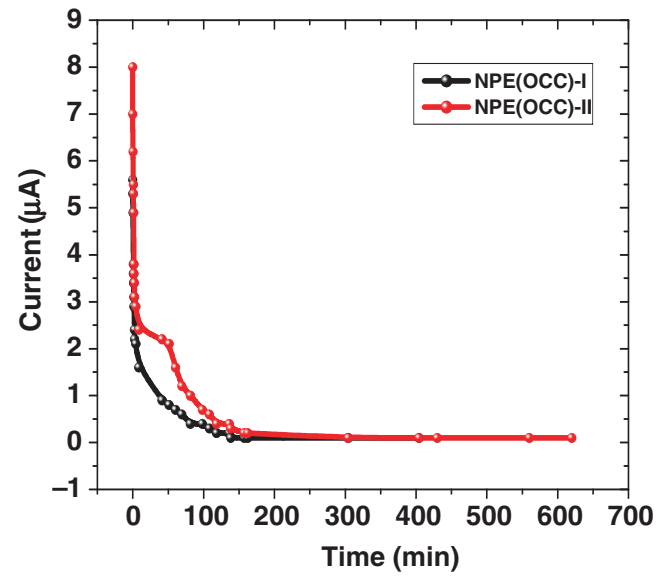

Figure 6. Variation of polarization current as a function of time.

\subsection{Physical characterization}

3.2a Thermal analysis by DSC of polymer electrolyte: The DSC thermograms for pure PEO, SPE (OCC), NPE (OCC)-I and NPE(OCC)-II are shown in figure $9 \mathrm{a}-\mathrm{d}$, respectively. The sharp endothermic peak observed at $69^{\circ} \mathrm{C}$ (in figure 9a) corresponds to the crystalline melting temperature $\left(T_{\mathrm{m}}\right)$ of pure PEO sample. ${ }^{25}$ For the salt added standard electrolyte SPE $\left(\mathrm{PEO}_{70} \mathrm{AgI}_{30}\right)$, the broad endothermic peak

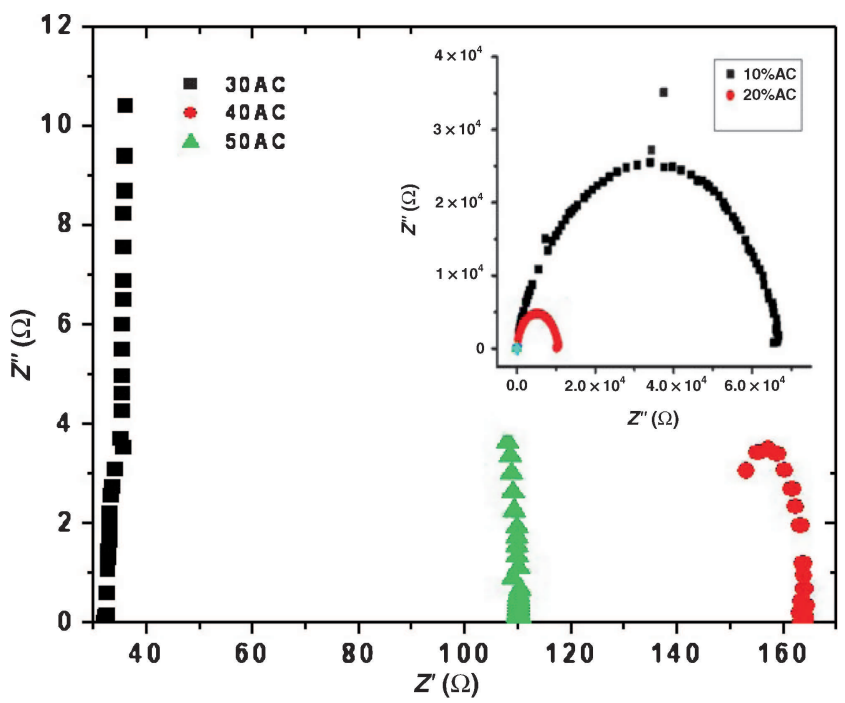

Figure 7. Cole-Cole plot of polymer-based PAC electrode.

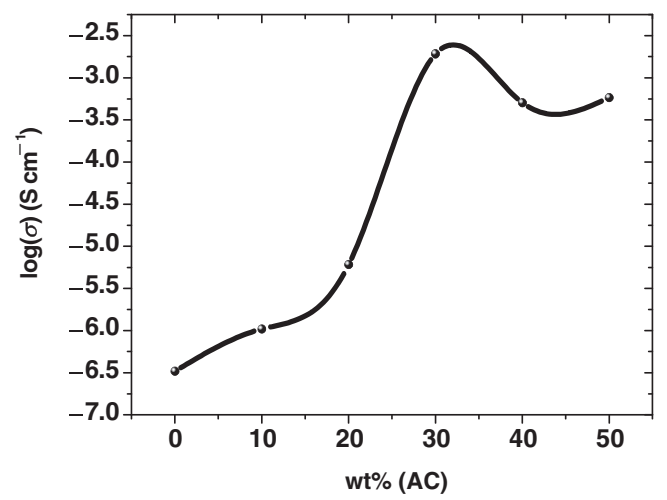

Figure 8. Conductivity of electrode with different weight percentages of activated carbon (AC).

Table 1. Effect of concentration of inorganic oxide filler on ionic conductivity $(\sigma)$, activation energy $\left(E_{\mathrm{a}}\right)$ and ion transference number $\left(t_{\text {ion }}\right)$ and compared these values with pure PEO and standard polymer electrolyte.

\begin{tabular}{lccrc}
\hline Specimen & $\begin{array}{l}\text { Ionic conductivity } \\
\left(\sigma\left(\mathrm{S} \mathrm{cm}^{-1}\right)\right)\end{array}$ & $\begin{array}{c}\text { Activation energy } \\
\left(E_{\mathrm{a}}(\mathrm{eV})\right)\end{array}$ & $\begin{array}{c}\text { Transference number } \\
\left(t_{\text {ion }}\right)\end{array}$ & Reference \\
\hline Pure PEO & $3.2 \times 10^{-9}$ & $\mathrm{NA}$ & 9 \\
SPE $(\mathrm{OCC})\left[\mathrm{PEO}_{70}: \mathrm{AgI}_{30}\right]$ & $3.3 \times 10^{-7}$ & 0.69 & 0.95 & 0.98 \\
NPE-I (OCC) $\left(\mathrm{PEO}_{70} \mathrm{AgI}_{30}\right)_{93}\left(\mathrm{Al}_{2} \mathrm{O}_{3}\right)_{7}$ & $5.78 \times 10^{-6}$ & 0.58 & Current work \\
NPE-II (OCC) $\left(\mathrm{PEO}_{70} \mathrm{AgI}_{3}\right)_{95}\left(\mathrm{SiO}_{2}\right)_{5}$ & $7.032 \times 10^{-6}$ & 0.1 & 0.98 & Current work \\
\hline
\end{tabular}




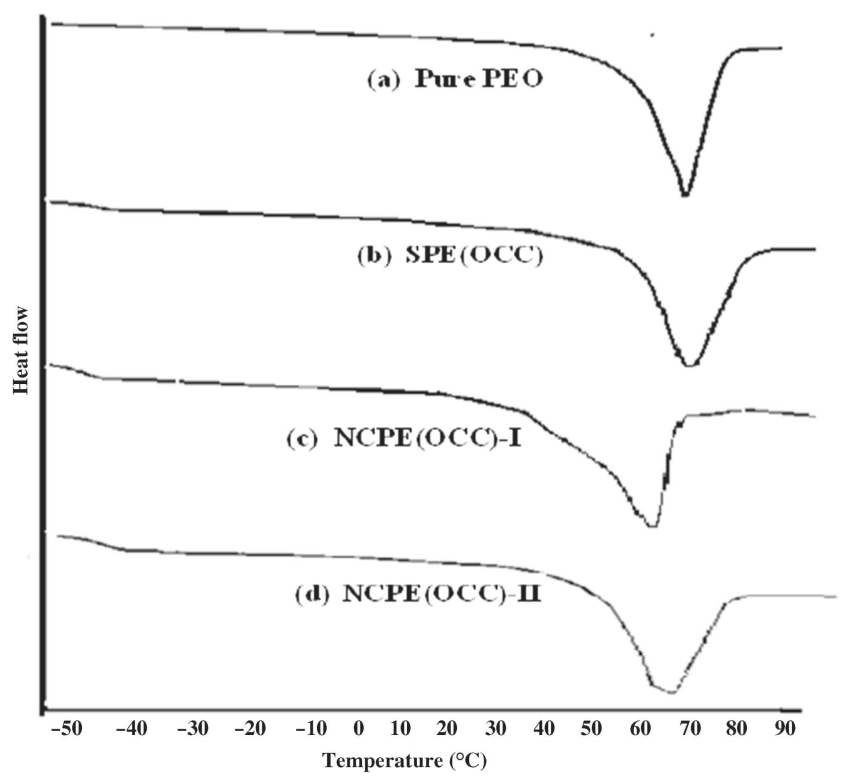

Figure 9. Differential thermal calorimetric of polymer electrolyte.

is shifted slightly to a lower value of $64^{\circ} \mathrm{C}$ (seen in figure $9 \mathrm{~b})$. The melting point temperature $\left(T_{\mathrm{m}}\right)$ continues to further decrease with the addition of filler to the standard electrolyte as seen in figure $9 \mathrm{c}$ and $\mathrm{d}$. The broad endothermic peak is now appeared to be at around $59^{\circ} \mathrm{C}$ for $7 \mathrm{wt} \% \mathrm{Al}_{2} \mathrm{O}_{3}$ and $5 \mathrm{wt} \% \mathrm{SiO}_{2}$ filler addition. Data reported in the literature ${ }^{26}$ for several polymer electrolyte systems reveal that there is a correlation between the melting temperature $\left(T_{\mathrm{m}}\right)$ and degree of crystallization suggesting that the factors related to stiffness of the polymer chain is influenced by the temperature. These observations clearly suggest that the enhancement in the ionic conductivity reflects the structural modifications associated with the polymer host caused by the additive filler.

3.2b TGA: Figure 10 shows the TGA curves of the polymer electrolytes and electrode. All the curves exhibit one main weight loss region but the temperature varies with respect to the additives involved. The TGA curve of the pure PEO (figure 10a) film appears to be quite dry with the weight loss of about $1.5-3 \%$ until $150^{\circ} \mathrm{C}$. This could be attributed to dehydration and the presence of chemically strong $\mathrm{H}_{2} \mathrm{O}$ bonding. No major weight loss is observed until $\sim 280^{\circ} \mathrm{C}$, however, a weight loss of $7 \%$ is seen which could be due to an irreversible decomposition. The major weight losses are only shown in the temperature range of $280-390^{\circ} \mathrm{C}$ abruptly $82 \%$ indicating that the film could be stable only up to $280^{\circ} \mathrm{C}$. The loss might correspond to the decomposition of $\mathrm{PEO},{ }^{27}$ burning of organic phase and the thermal dehydration of inorganic particles. No further weight loss was observed for PEO after $500^{\circ} \mathrm{C}$. For $30 \% \mathrm{AgI}$ additive, standard electrolyte, figure $10 \mathrm{~b}$ shows that the transition region shifted to a higher temperature, indicating the interaction between the components could occur that led to mutual stabilization. A similar

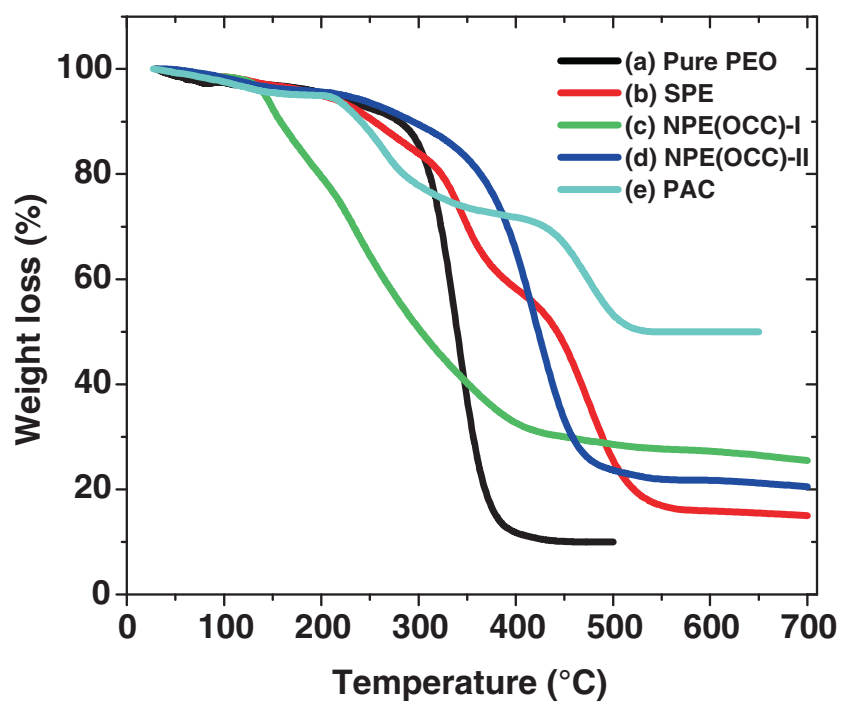

Figure 10. Thermogravimetric analysis (TGA) of polymer electrolytes: (a) pure $\mathrm{PEO}$, (b) standard electrolyte $\left(\mathrm{PEO}_{70} \mathrm{AgI}_{30}\right)$, (c) NPE(OCC)-I, (d) NPE(OCC)-II and (e) PAC electrode.

trend of weight loss of around $3 \%$ is observed up to $150^{\circ} \mathrm{C}$, which is attributed to the removal of moisture or residue solvent in the film. ${ }^{28}$ The weight loss substantially increases up to $17 \%$ at $230^{\circ} \mathrm{C}$ and then to $79 \%$ at $\sim 570^{\circ} \mathrm{C}$. The results clearly indicate that although the transition region occurred at an early temperature $\left(230^{\circ} \mathrm{C}\right)$ the film could sustain for a high temperature. The shift in temperature for weight loss illustrates that the thermal stability enhances when $\mathrm{AgI}$ is added to the polymer electrolyte. Thus, standard electrolyte is thermally more stable as compared with liquid electrolyte and preferred when used in portable electrochemical energy storage devices, i.e., capacitor and battery. In the case of $\mathrm{Al}_{2} \mathrm{O}_{3}$ filler as an additive as shown in figure 10c, a remarkable weight loss of $75 \%$ is observed only between temperatures 320 and $500^{\circ} \mathrm{C}$, similarly figure $10 \mathrm{~d}$ shows a percentage weight loss of $5 \mathrm{wt} \% \mathrm{SiO}_{2}$ at various temperatures. Weight loss of $70 \%$ is obtained in second transition region between temperatures around 110 and $450^{\circ} \mathrm{C}$. It is also seen in figure 10e that PAC electrode shows three-step decomposition behaviour corresponding to three different components present in it. The major weight loss is in between 213 and $530^{\circ} \mathrm{C}$. The first step is due to the decomposition of PEO-salt membrane and second step is due to PEO-AC decomposition.

3.2c SEM and EDS: The SEM images of the polymer electrolytes and electrode along with their EDS spectra is shown in figure 11. SEM was carried out to investigate the effect of salt (AgI), nano-sized fillers $\left(\mathrm{Al}_{2} \mathrm{O}_{3}\right.$ and $\left.\mathrm{SiO}_{2}\right)$ and $\mathrm{AC}$ on the SPE. The surface morphology of the pure PEO is seen to be rough (figure 11a) with a lot of wedges, it could be associated with high surface energy facilitating the adherence of particles to the nucleus that enhances the kinetics of nucleation. ${ }^{29,30}$ With the addition of salt $(30 \% \mathrm{AgI})$ to the 

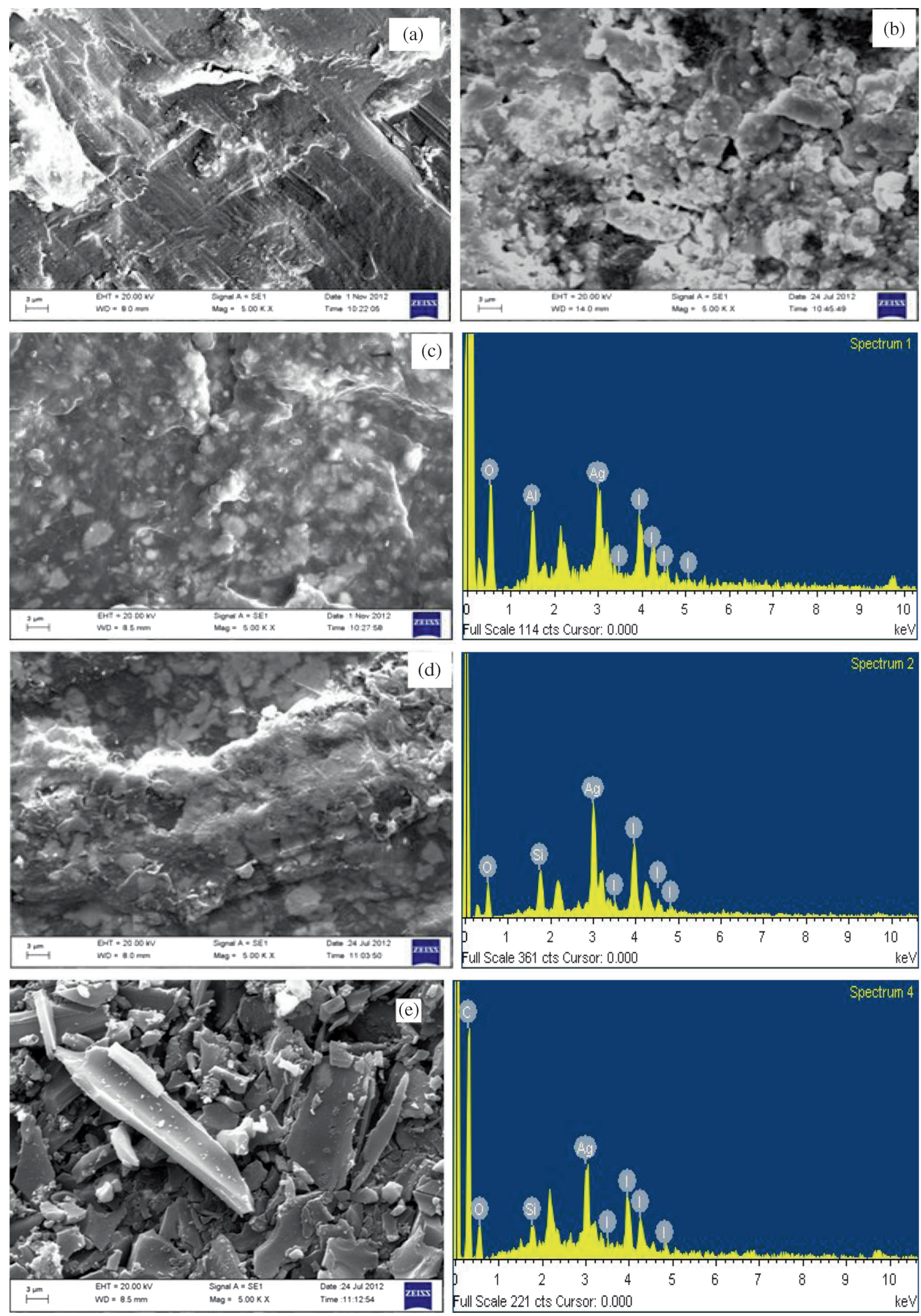

Figure 11. Scanning electron microscopy and EDS spectra of (a) pure PEO, (b) standard electrolyte, (c) NPC(OCC)-I, (d) (NPC(OCC)-II and (e) PAC electrode. 
pure PEO, the surface morphology of the standard electrolyte appears to be smooth in figure $11 \mathrm{~b}$ and the particle size tends to be smaller. The addition of $\mathrm{Al}_{2} \mathrm{O}_{3}$ and $\mathrm{SiO}_{2}$ further modified the surface morphology. The brighter spots in the SEM images is analysed through elemental analysis (figure 11c) and found to be $\mathrm{Al}_{2} \mathrm{O}_{3}$ particles as fillers which is homogeneously distributed within the electrolyte. Similarly figure 11d shows along with amorphous phase there is an ordering with the addition of $\mathrm{SiO}_{2}$. It may help in ion transport in electrolyte in order to increase ionic conductivity. ${ }^{31,32}$

Figure 11e shows that the carbon content uniformly distributed in PEO, which is seen in morphograph by coal like shape, rough surface morphology and large number of porosity. There are large number of cracks and voids in the surface of electrode which improve the surface area. High porosity of AC provides a large surface area for the attachment of salt due to which large numbers of ions accumulated at the electrode which results in high capacitance. The EDS fingerprint along with SEM indicates the presence of element in electrolyte and electrode.

3.2d X-ray diffraction analysis of polymer electrolyte: Figure 12 compares the X-ray diffraction pattern of the polymer electrolytes. The typical X-ray diffraction pattern with a characteristic peak at $24^{\circ}$ (figure 12a) corresponds to the pure PEO material. When AgI salt is added to pure PEO, new diffraction peaks at around $40^{\circ}$ and $47^{\circ}$ starts to emerge (figure 12b), while the peak corresponding to the initial PEO around $20^{\circ}$ shows the decrease in intensity (to be noted, scales in the $Y$ axes are different). With the addition of $\mathrm{Al}_{2} \mathrm{O}_{3}$ and $\mathrm{SiO}_{2}$ fillers to the standard electrolyte $\left(\mathrm{PEO}_{70} \mathrm{AgI}_{30}\right)$ decreases the peak intensities further (shown in figure $12 \mathrm{c}$ and d) reflecting that the nature of the material, i.e., NPE(OCC)-I and NPE(OCC)-II are getting more amorphous, this is an indication of highly conducting polymer ${ }^{30}$ which is more suitable to be used as electrolyte membrane in the energy storage devices. The results based on the above observations confirm that the reported NPE(OCC)s electrolyte film possess an amorphous phase. Unfortunately, due to very small amount of $\mathrm{Al}_{2} \mathrm{O}_{3}$ and $\mathrm{SiO}_{2}$ fillers which is below the detection limit of $\mathrm{X}$-ray measurement and hence the characterization of their peaks using X-ray diffraction experiments becomes cumbersome. This could be the reason that we could not identify any peaks corresponding to fillers in figure 12 .

\subsection{Formation and characterization of capacitor}

With the use of PAC(OCC) electrode, NPE(OCC) electrolyte, and egg cell membrane (ESM) as a separator two thin capacitors are constructed. ESM sandwiched between two identical electrolyte and electrode. The whole cell was sealed under gradually increasing pressure of about $2.5-3 \mathrm{t} \mathrm{cm}^{-2}$ and its performance was characterized using impedance spectroscopy (IS), cyclic voltammetry (CV), discharge characteristics and leakage current profile.

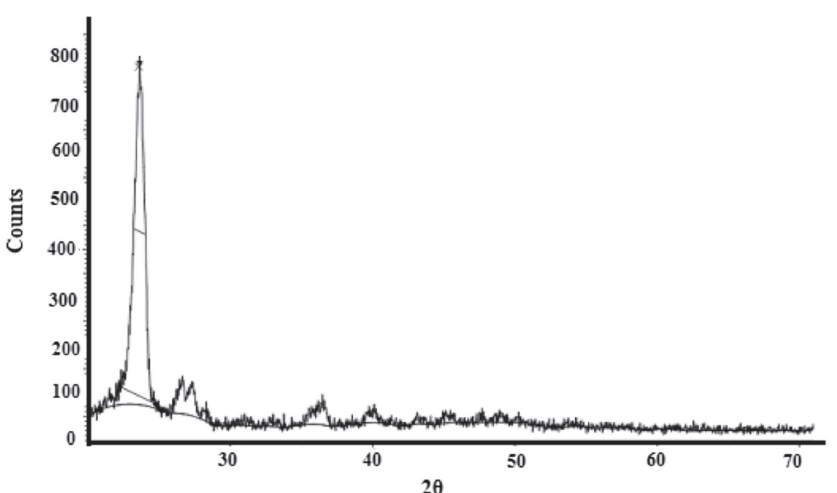

(a) Pure PEO

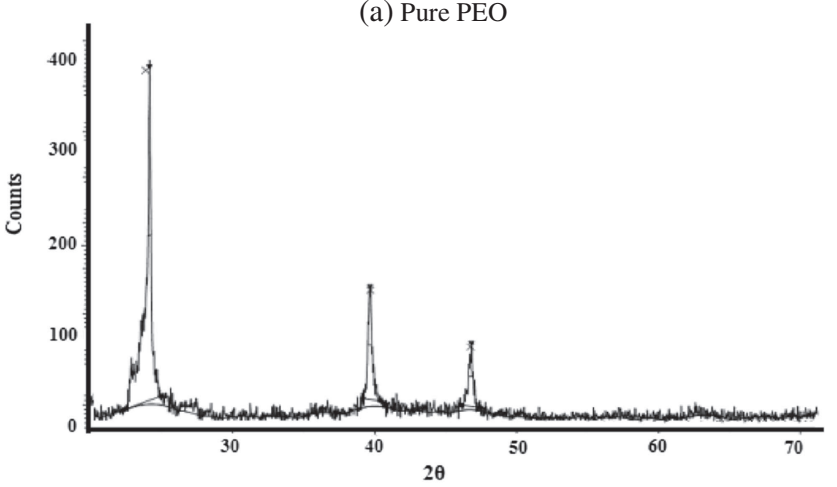

(b) Standard electrolyte $\left(\mathrm{PEO}_{70} \mathrm{AgI}_{30}\right)$

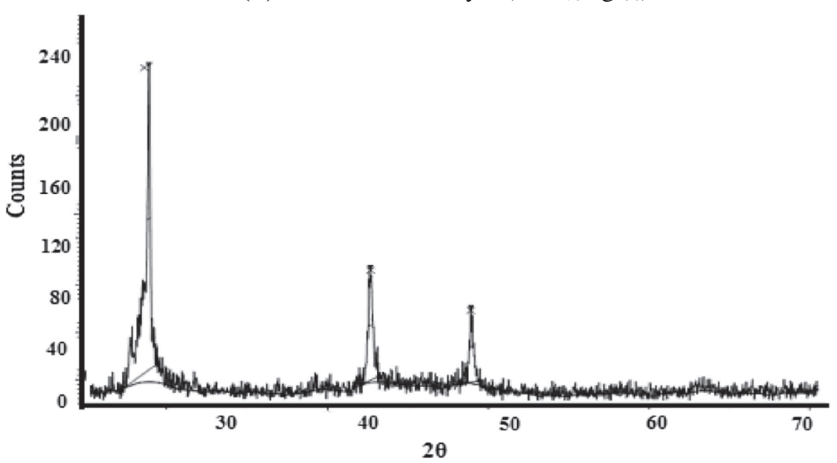

(c) $\left(\mathrm{PEO}_{70} \mathrm{AgI}_{30}\right)_{93}\left(\mathrm{Al}_{2} \mathrm{O}_{3}\right)_{7}$

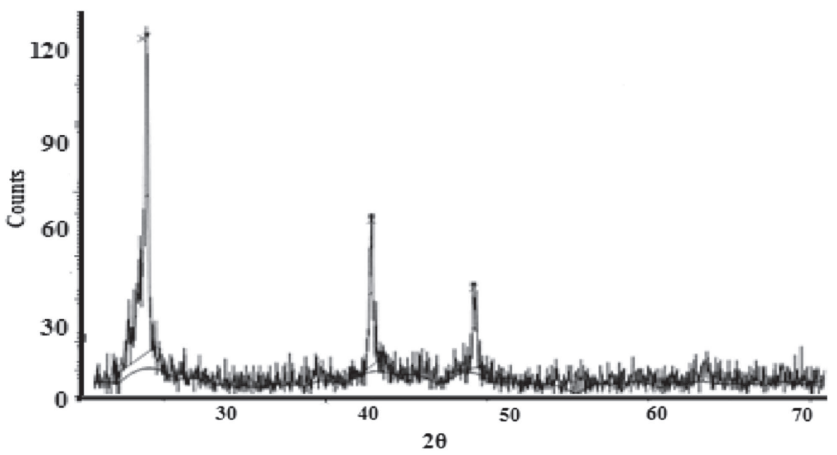

(d) $\left(\mathrm{PEO}_{70} \mathrm{AgI}_{30}\right)_{95}\left(\mathrm{SiO}_{2}\right)_{5}$

Figure 12. X-ray diffraction pattern of the polymer electrolytes: (a) pure $\mathrm{PEO},(\mathbf{b})$ standard electrolyte $\left(\mathrm{PEO}_{70} \mathrm{AgI}_{30}\right),(\mathbf{c})$ $\left(\mathrm{PEO}_{70} \mathrm{AgI}_{30}\right)_{93}\left(\mathrm{Al}_{2} \mathrm{O}_{3}\right)_{7}$ and (d) $\left(\mathrm{PEO}_{70} \mathrm{AgI}_{30}\right)_{95}\left(\mathrm{Si}_{2}\right)_{5}$.

3.3a Impedance spectroscopy analysis of capacitors: Figures 13 and 14 represent the Cole-Cole plots of capacitor- 1 and capacitor-2, respectively, here a straight line parallel to the 


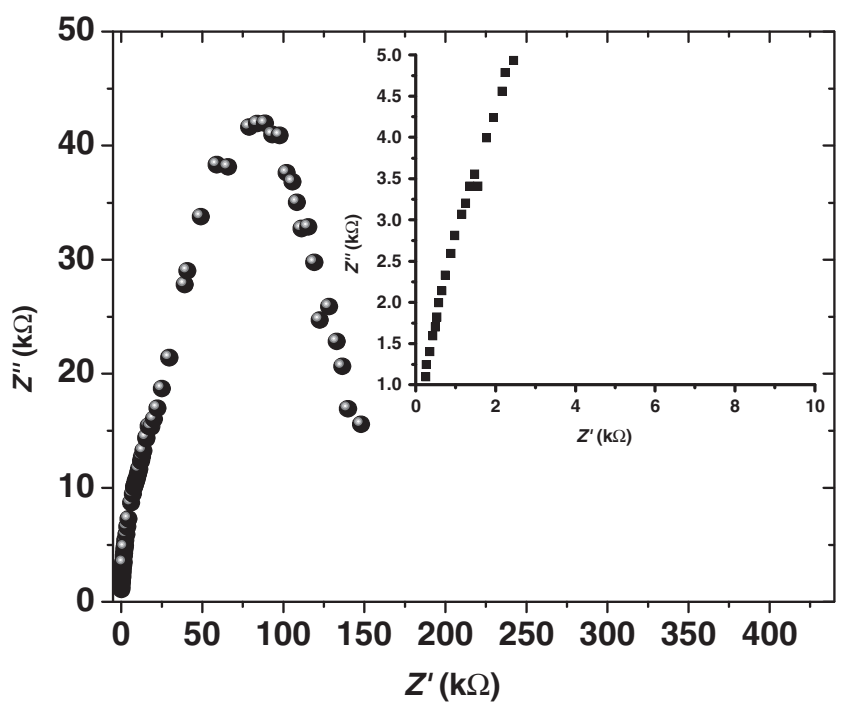

Figure 13. Cole-Cole plot of capacitor-1.

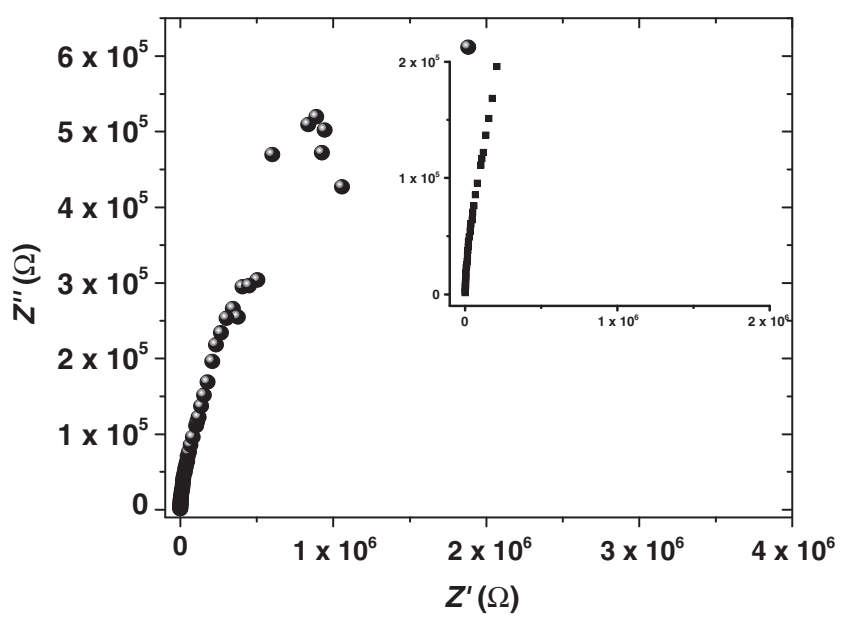

Figure 14. Cole-Cole plot of capacitor-2.

imaginary axis at high-frequency region, showing typical behaviour of dielectric capacitor or an ideal electrolyte capacitor (EDCL). The internal cell resistance or series resistance found for capacitor- 1 and capacitor-2 are 190.04 and 196.91 $\Omega$, respectively. It concludes that, at higher frequencies, the plots assume a shape close to that of an ideal capacitor and the points are almost dispersed in a vertical line. The resistance characteristics of the different supercapacitors are expressed by the so-called electric series resistance (ESR), which includes the electrolyte resistance, the collector/electrode contact resistance, and the electrode/electrolyte interface resistance. The use of NPEs as an electrolyte in supercapacitor decreases cell resistance. However, there is not much difference in cell resistance while using NPE(OCC)-I and $\mathrm{NPE}(\mathrm{OCC})-\mathrm{II}$ as electrolyte. This is because separator resistance is larger contributor to the cell resistance, which is much longer than electrode and electrolyte.

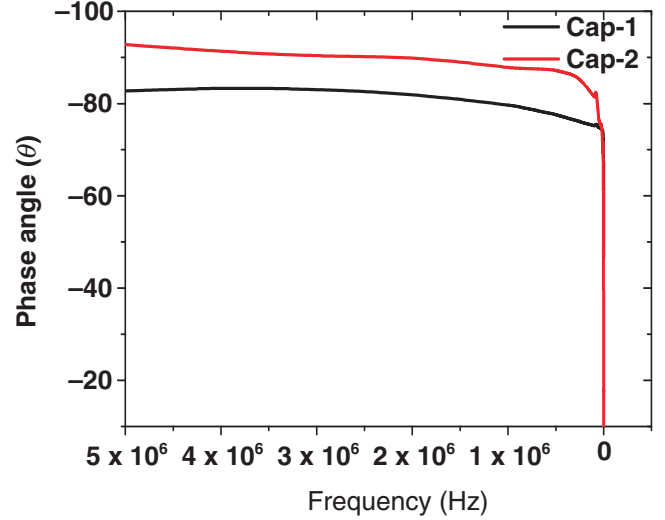

Figure 15. Bode plot of capacitor-1 and capcitor-2.

Figure 15 shows the Bode plot for both capacitors. The impedance for capacitor is given by $Z=0-j(1 / \omega C)$; therefore, the magnitude and the phase angle is given by $|Z|=$ $1 / \omega c$ and $\varphi=\tan ^{-1}(-\infty)=-90^{\circ}$, respectively. The phase angle for both supercapacitor is found very close to $-90^{\circ}$, this again indicates that the prepared electrochemical cell are capacitors. It also shows that these capacitors have capacitive behaviour at frequency higher than $10^{3} \mathrm{~Hz}$.

3.3b CV analysis: It is observed that the shape of $\mathrm{CV}$ curves are nearly rectangle and symmetry or mirror image about their zero current line, which is a clear proof of welldeveloped capacitance properties. There is slightly difference between the CV curve it is because of the type of electrolyte used which affect the performance of capacitors. Using equations

$$
C=\frac{Q}{V_{\mathrm{r}}} \frac{1}{m} \quad \text { and } \quad P=\frac{\operatorname{Max}(i \times V)}{m}
$$

specific capacitance and power of both capacitors are found to be $2.56 \mathrm{~F} \mathrm{~g}^{-1}, 1.119 \mathrm{~mW} \mathrm{~g}^{-1}, 1.94 \mathrm{~F} \mathrm{~g}^{-1}$ and $2.1 \mathrm{~mW} \mathrm{~g}^{-1}$, respectively.

3.3c Leakage current and discharge curve of capacitor: In order to limit the relaxing phenomena effect on the selfdischarge measurement, both capacitors charged with a constant voltage $(2.0 \mathrm{~V})$ supply for about $12 \mathrm{~h}$. All the components of the capacitor cells are approximately charged to the same potential. When the charging current is stopped, the decrease in voltage across the capacitor follows only the effect of self-discharge. The voltage is measured by using digital voltmeter with respect to time which is shown in figure 16. It is seen that the curve between 2.0 and $1.0 \mathrm{~V}$ decreases abruptly then gradually. It also illustrates that the self-discharge rates of capacitors are different. The selfdischarge slows down after several hours, because some mechanisms diminish. Thus, the capacitor returns gradually to the stable state. ${ }^{33-35}$ Real capacitors require a current called leakage current $I_{\text {leakage }}$ to maintain constant voltage, it slowly discharge a charged capacitor that has no external connections to its terminals and this process is called 


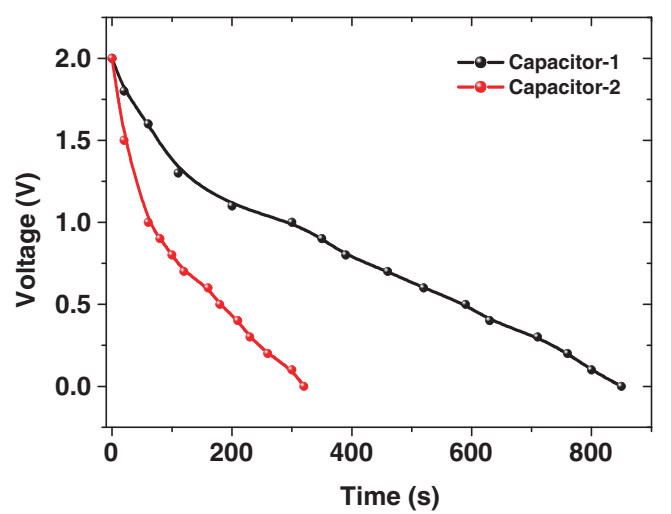

Figure 16. Discharge characteristics of experimental capacitors.

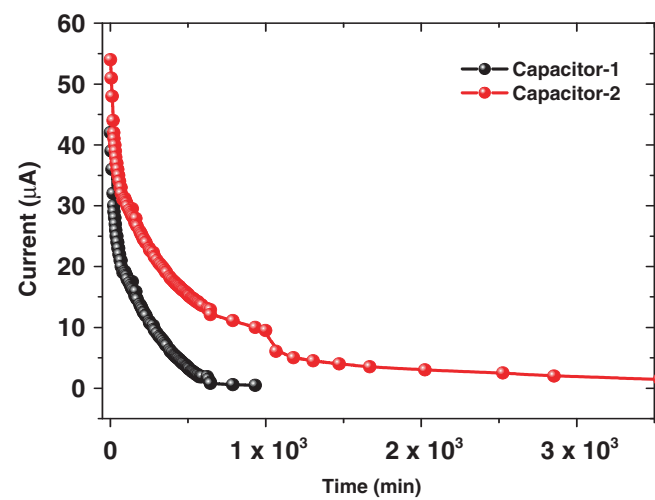

Figure 17. Leakage current characteristics of capacitors.

self-discharge. It is measured by applying a DC voltage to the capacitor and the current required to maintain that voltage. Relatively small direct current flows through a capacitor when a voltage is applied across it. Because of the special properties of the polymer electrolyte, a small current will continue to flow even after a DC voltage has been applied for longer period called the leakage current. Figure 17 shows that a high leakage current flows in the first minutes after applying voltage to the capacitor, in particular after prolonged storage without any applied voltage. In the course of continuous operation, the leakage current will decrease and reach an almost constant 'steady-state' value. Low leakage current obtained from all capacitors is the indicative that the electrochemical cells are well-designed capacitors.

\section{Conclusions}

Novel $\mathrm{Ag}^{+}$conducting nanocomposite polymer electrolyte synthesized by the hot-press technique by dispersing inorganic nano-fillers $\mathrm{Al}_{2} \mathrm{O}_{3}$ and $\mathrm{SiO}_{2}$ in appropriate wt $\%$ in the standard electrolyte $\left(\mathrm{PEO}_{70} \mathrm{AgI}_{30}\right)$. The optimum composition was found for $7 \% \mathrm{Al}_{2} \mathrm{O}_{3}$ and $5 \% \mathrm{SiO}_{2}$ having conductivities $(\sigma) \sim 5.78 \times 10^{-6}$ and $7.032 \times 10^{-6} \mathrm{~S} \mathrm{~cm}^{-1}$, respectively. The activation energy $E_{\mathrm{a}}$ is determined for the different compositions of NPEs and found that the lowest value of $E_{\mathrm{a}}$ is an indicative of relatively easy ion migration through polymer electrolyte. Ionic nature is confirmed by ion transference $\left(t_{\text {ion }}\right)$ calculation. All the physical characterizations were studied on the best chosen material NPE(OCC). The thermal behaviour studied for these materials suggests that they are thermally stable up to $240^{\circ} \mathrm{C}$ and suitable for device applications. The XRD and SEM analyses show that the addition of inorganic filler reduces the degree of crystallinity while enhancing the ionic conductivity. The best chosen electrolytes were tested in the symmetric capacitor comprising of polymer-based electrodes $\left(\mathrm{PEO}_{70} \mathrm{AgI}_{30}\right)_{70}(\mathrm{AC})_{30}$ (PAC). The fabricated capacitors show comparatively good performance. The discharge and leakage current profiles show that the fabricated electrochemical cell is capacitor. The capacitive nature of electrochemical cell is due to high surface area of AC. Relatively high conducting electrolyte of capacitor- 1 and -2 easily release ions, which can penetrate deeply into the surface of electrode, it yields a high capacitance value. It can be concluded that these materials can be the best alternative for the fabrication of high capacitance capacitors.

\section{References}

1. Wen T C, Tseng H S and Cheng T T 2000 Ind. Eng. Chem. Res. 3972

2. Itoh $\mathrm{T}$, Fujita $\mathrm{K}$, Inoue $\mathrm{K}$, Iwama $\mathrm{H}$, Kondoh $\mathrm{K}$, Uno $\mathrm{T}$ and Kubo M 2013 Electrochim. Acta 112221

3. Abdul Samad Y, Asghar A and Hashaikeh R 2013 Renew. Energy 5690

4. Scrosati B 1995 Nature 373557

5. Appetecchi G B, Hassoun J, Scrosati B, Croce F, Cassel F and Salomon M 2003 J. Power Sources 124246

6. Wright P V 1975 Brit. Polym. J. 7319

7. Armand M B, Chabgno J M and Duclot M J 1978 Second international conference on solid electrolytes. St. Andrews, Scotland, September 20-22

8. Murata K, Izuchi S and Yoshihisa Y 2000 Electrochim. Acta 451501

9. Agrawal R C and Pandey G P 2008 J. Phys. D: Appl. Phys. 41 18

10. Gadjourova N, Andreev Y G, Tunstall D P and Bruce P G 2001 Nature $\mathbf{4 1 2} 520$

11. Golodnitsky D, Ardel G and Peled E 2002 Solid State Ion. 147 141

12. An S Y, Jeong C, Won M S, Jeong E D and Shim Y B 2009 J. Appl. Electrochem. 391573

13. Wieczorek W 1995 Electrochim. Acta 402031

14. Masoud E M, Bellihi A-A, Bayoumy W A and Mousa M A 2013 J. Alloys Compd. $\mathbf{5 7 5} 223$

15. Croce F, Appetecchi G B, Persi L and Ronci F 1998 Nature 394456

16. Dissanayake M A K L, Jayathilaka P A R D, Bokalawala R S P, Albinsson I and Mellander B E 2003 J. Power Sources 409119 
17. Verma M L and Singh N K 2012 Mater. Sci. Res. India 9139

18. Wagner Z 1933 J. Phys. Chem. B 2125

19. Wagner J B and Wagner C 1957 J. Chem. Phys. 261597

20. Swierczynski D, Zalewska A and Wieczorek W 2001 Chem. Mater. 131560

21. Polu A R and Kumar R 2013 Adv. Mater. Lett. 4543

22. Prsyluski J, Siekierski M and Wiecsorek W 1995 Electrochim. Acta $\mathbf{4 0} 2101$

23. Cowie J M G and Martin A C S 1987 Polymers 28627

24. Reddy M J, Sreekanth T, Chandrasekhar M and Rao U V S 2000 J. Mater. Sci. 352841

25. Chu P P, Reddy M J and Kao H M 2003 Solid State Ion. 156 141

26. Ibrahim S, Yasin S M M, Nee N M, Ahmad R and Johan M R 2012 J. Non-Cryst. Solids 358210
27. Caykara T, Demirci S, Eroglu M S and Guven O 2005 Polymer 4610750

28. Uma T, Mahalingam T and Stimming U 2005 Mater. Chem. Phys. 90239

29. Chu W C, Chiang S-F, Li J G and Kuo S W 2013 Materials 6 5077

30. Robitaille C D and Fauteux D 1986 J. Electrochem. Soc. 133 315

31. Kim J W, Ji K-S, Lee J P and Park J W 2003 J. Power Sources 415119

32. Yap Y L, You A H, Teo L L and Hanapei H 2013 Int. J. Electrochem. Sci. 82154

33. Conway B E 1991 J. Electrochem. Soc. 1381539

34. Dell R and Rand D A J 2001 J. Power Sources 1002

35. Tanaka T, Ohta K and Arai N 2001 J. Power Sources 97-98 2 